International Review of Research in Open and Distributed Learning Volume 16, Number 6

November - 2015

\title{
Theories and Applications of Massive Online Open Courses (MOOCs): The Case for Hybrid Design
}

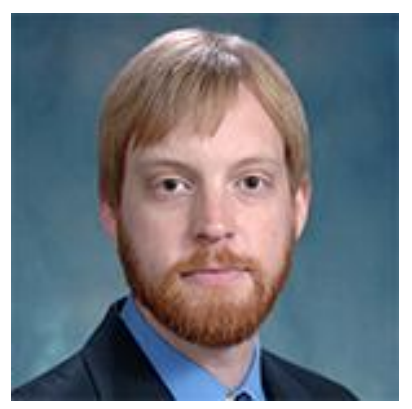

Abram Anders

University of Minnesota Duluth, United States

\begin{abstract}
Initial studies of learning in massive open online courses (MOOCs) primarily focused on participation patterns and participant experiences. More recently, research has addressed learning theories and offered case studies of different pedagogical designs for MOOCs. Based on a meta-analysis and synthesis of the research literature, this study develops a conceptual model of prominent theories and applications of MOOCs. It proposes a continuum of MOOC learning design that consolidates previous theories into a tripartite scheme corresponding to primary types of MOOCs including content-based, community/tasked-based, and network-based applications. A series of MOOC hybrids are analyzed to demonstrate the value of this model while also clarifying appropriate applications and significant design challenges for MOOCs. Results indicate that hybrid design may support the greatest diversity of learners and scaffold engagement with networked and emergent learning contexts.
\end{abstract}

Keywords: Blended Learning, Connectivism, cMOOCs, Emergent Learning, Heutagogy, Hybrid Moocs, Massive Open Online Courses (MOOCs), xMOOCs 


\section{Introduction}

The field of open and distributed learning has experienced a surge of media coverage and public interest in the last several years, largely focusing on the phenomenon of massive open online courses (MOOCs). The term MOOC has been used to describe a diverse set of approaches and rationales for offering large-scale online learning experiences. MOOCs have been delivered using both centralized platforms and services including learning management systems (LMSs) and decentralized networks based on aggregations of blog sites and social media feeds. MOOCs have been designed to support university curricula, academic scholarship, community outreach, professional development, and corporate training applications.

Following the schema of the Gartner "hype cycle," it can be argued that MOOCs reached the "peak of inflated expectations" in 2012, crashed into the "trough of disillusionment" in 2013 and 2014, and are now poised to climb the "slope of enlightenment" in which practical applications and long term impacts may gradually be fulfilled (Gartner, 2015). In 2012, the famed "Year of the MOOC" that included the founding of start-up MOOC providers edX, Coursera, and Udacity, MOOCs were heralded as innovations that would both increase access and decrease costs of university education (Pappano, 2012). However, by 2013 and 2014, an anti-MOOC backlash was in full swing. Critics of the MOOC movement cited low completion rates, high development costs, and demographic data that showed MOOC participants in most open courses were primarily welleducated professionals (Fischer, 2014; Hill, 2013; Selingo, 2014).

Though some early expectations have proven unrealistic, MOOCs are a maturing technological innovation. End of the year statistics for 2014 show a rapidly expanding MOOC market including more than 400 universities offering more than 2400 courses to nearly 18 million students (Shah, 2014). It is also worth noting the expanding role and scope of providers outside the United States. MiriadaX, a service delivering courses to a world-wide market of Spanish speakers, reached 1 million users in 2014. Similarly, European providers including FutureLearn and iversity and the Australia provider Open2Study are growing in market share, as are the numbers of MOOCs offered independently by universities and other institutions. Complementing this greater diversity of MOOC practitioners and stakeholders is the growing integration of MOOC research and practices in the literature of open, distance, and distributed learning.

As noted in a 2013 meta-study of literature on MOOCs, initial research has largely focused on learner perspectives, behaviors, and participation patterns in MOOC environments (Liyanagunawardena, Adams, \& Williams, 2013). However, as MOOCs mature and spread, it is important to understand the opportunities and appropriate applications of MOOCs both in terms of theories of learning and pedagogical design choices. Based on a synthesis of theories of online and distributed learning, this study develops a conceptual map positing a continuum of MOOC learning and taxonomy of MOOC types. This model frames an analysis of MOOC case studies addressing key features and essential qualities of MOOC design. Results indicate that hybrid

This work is licensed under a Creative Commons Attribution 4.0 International License. 
MOOC designs can support the greatest diversity of real-world learners and facilitate growth of capacities for networked and emergent learning styles.

\section{MOOCs and Emergent Learning}

The earliest MOOCs and the MOOC name itself emerged from the work of Canadian scholars Stephen Downes and George Siemens (Hill, 2012). Beginning in 2008, Downes and Siemens led a series of MOOCs including, among others, "Connectivism and Connective Knowledge" (CCKo8), "Personal Learning Environments Networks and Knowledge” (PLENK2010), and "Change11." These courses were envisioned as a testing ground for their theories of connectivism and connective knowledge (Downes, 2012; Siemens, 2005, 2006). In contrast to previous theories of learning and pedagogy, Downes and Siemens offered a radically network-based account for processes of learning and knowledge production in the Information Age.

Connectivist MOOCs (cMOOCs) are designed to generate network effects for learning. Network effects can be defined as demand-side economies of scale in which the growing demand and use of a service or product adds to its value (Stewart, 2013). Following the logic of network effects, the massiveness of cMOOCs is valuable insofar as it offers an increasing diversity and density of potential connections among its participants, information nodes, tools, and resources. The openness of cMOOCs and the relative autonomy of participants allow these connections to be formed without the mediation of a centralized authority. The goal of cMOOCs is to facilitate emergent, self-organized patterns of collaborative learning. Downes has argued that connectivist learning is based on four primary principles: "autonomy, diversity, openness, and connectedness/interactivity” (Milligan, Littlejohn, \& Margaryan, 2013, p. 150).

In order to implement these principles, cMOOCs are designed to be readily accessible and to allow learners to participate using their own blog sites and social media accounts. The course website may host little more than a set of freely available readings and a schedule of weekly webinars hosted by guest lecturers. This minimalist agenda constitutes a common context and topical focus for learning that takes place across the network of the web in a decentralized way. The real activity of cMOOCs takes place in postings and commentary on participant blogs, social media discussions, video-chats, and other online events. The key component of most cMOOCs is a shared hashtag that aggregates these activities into a shared stream available to all participants. In cMOOCs led by Downes and Siemens, this shared stream has taken the form of a daily email with links to participant blog and social media posts, and upcoming virtual events. In other approaches, postings and activity may be aggregated and hosted on a course website.

This basic set of features is extremely adaptable. Many cMOOCs operate like discussion-based seminars for a set of weekly readings and webinars. Others may be built around structured activities including tasks and projects that facilitate the development of specific skill or competencies. The essential point is that in cMOOCs the learning experiences are networked,

This work is licensed under a Creative Commons Attribution 4.0 International License. 
open, and decentralized. A single individual may participate in multiple courses and engage multiple sets of overlapping connections across them. The history and artifacts of these learning experiences will continue to be available on the individual's blog and social media accounts. Connectivist learners develop and maintain portfolios of their individual learning while also contributing to the growth of networks of connected and connective knowledge over time (Downes, 2012).

However, the decentralized, networked approach advocated by connectivism is not the only or even the most widely recognized model for MOOCs. Broader media attention and academic interest in MOOCs really began in 2011 with "Introduction to Artificial Intelligence," a course offered by Sebastian Thrun and Peter Norvig at Stanford. This course enrolled over 160,000 participants from all over the world and pioneered a more centralized, content-focused approach to MOOCs (Hill, 2012). Downes coined the acronym xMOOCs to designate this type of MOOC, which includes courses offered through the cloud-based learning management platforms of startup MOOC providers edX, Coursera, and Udacity. In addition to adapting traditional LMS functions for use at scale, these platforms offer enhanced options for creating and delivering multimedia instructional content.

Rodriquez (2012) has argued that courses offered through xMOOC platforms predominantly employ a cognitive-behaviorist or instructivist pedagogical approach. Following the taxonomy developed by Anderson and Dron (2011), cognitive-behaviorism is the first of three generations of distance education pedagogical theory; it is exemplified by content-based training delivered at scale through a one-to-many distribution model. Most xMOOC courses are delivered as a professionally produced video lecture series, typically delivered by a single professor. Videos are designed to be short, 4-5 minutes, and feature integrated quizzes to help students maintain focus and retain the material. The learning process may also be supported by short readings, practice problems and cases, and summative testing.

Though the interface design and feature set of these platforms is generally geared toward a content transmission model of learning, xMOOC designers and facilitators have also experimented with a range of social and collaborative activities to better integrate the insights of social-constructivist pedagogical theories (Poplar, 2014). Social-constructivism, the second generation of pedagogical theory, posits that "each learner constructs means by which new knowledge is both created and integrated with existing knowledge" (Anderson \& Dron, 2011, p. 85). In this process, social context and relationships with other individuals are seen as crucial to a process of negotiating meaning and developing new skills. The educational practices of this tradition emphasize socially-intensive and interactive learning experiences, often in small groups supported by the instructor as interlocutor and facilitator.

In contrast to cognitive-behaviorism and social-constructivism, connectivism eschews a focus on both content-driven and instructor-mediated learning experiences. While it shares a commitment to socially-negotiated and relationally-constructed knowledge, this third generation of pedagogy 
further decenters the role of educator as knowledge expert and learning mediator (Anderson \& Dron, 2011). Williams, Karousou, and Mackness (2011) have characterized cMOOCs as offering a style of "emergent learning" that is "self-organized and typically collaborative. It is open and is created and distributed by learners themselves" (p. 43). These learning conditions facilitate "learning which arises out of the interaction of a number of people and resources, in which the learners organize and determine both the process and to some extent the learning destinations, both of which are unpredictable" (p. 43).

Corroborating the analysis of Anderson and Dron (2011), multiple studies have argued for distinguishing emergent learning from traditional forms of prescriptive learning (Williams et al., 2011; Williams, Mackness, \& Gumtau, 2012). In prescriptive learning, predetermined learning paths are charted through hierarchical and highly formalized bodies of knowledge. Based on this definition, prescriptive learning is highly correlated with cognitive-behaviorist or instructivist pedagogies and xMOOCs. In contrast, emergent learning is based on learner-determined and selforganized processes that engage complex, unpredictable, and evolving domains. It leads to the serendipitous discovery of adaptive solutions to situated problems (Saadatmand \& Kumpulainen, 2013; Kop, 2012). Emergent learning is highly correlated with connectivism and cMOOCs, especially with an emphasis on leveraging network connections to solve problems and to grow capacities for self-directed learning.

It is this latter quality that has led recent scholarship to explore connectivism in terms of the theory of heutagogy. Blaschke (2012) has defined heutagogy as the "study of self-determined learning." (p. 58). In heutagogy, the instructor "fully relinquishes ownership of the learning path and process to learner, who negotiates learning and determines what will be learned and how it will be learned" (p. 59). This corresponds to a shift in emphasis from the acquisition of specific skills and competencies to the development of capabilities or capacities, distinguished by an emphasis on self-efficacy and broader applications in collaborative and problem solving contexts.

As with emergent and prescriptive learning, this heutagogic spectrum is correlated with a basic taxonomy of MOOC types positing instructivist-style xMOOCs as corresponding to pedagogy and connectivist-style cMOOCs as corresponding to heutagogy (Beaven, Hauck, Comas-Quinn, Lewis, $\&$ de los Arcos, 2014). The complete heutagogic model includes three stages moving from pedagogy, to andragogy, to heutagogy. In pedagogy, less mature learners are supported by high levels of instructor control and course structure. In andragogy, more mature, adult learners selfdirect learning within the framework of a course design and with instructor guidance. Finally, in heutagogy, the learner has the highest level of autonomy, self-directing the learning path and selfdetermining learning goals (Beaven et al., 2014; Blaschke, 2012).

This work is licensed under a Creative Commons Attribution 4.0 International License. 


\section{A Diversity of Theories and Applications}

Based on a synthesis of previous literature, a conceptual model can be framed for a continuum of MOOC learning that integrates multiple theories and applications of MOOCs (see Table 1). MOOCs are first situated along a spectrum from prescriptive learning to emergent learning (Williams et al., 2011; Williams et al., 2012). Complementing this perspective, the taxonomy developed by Anderson and Dron (2011) is used to chart a resonant progression in online learning theory from cognitive-behaviorism through social-constructivism to connectivism. Research framing relationships between instructor control, course structures, and learner autonomy establishes a progression from pedagogy, to andragogy, to heutagogy. Finally, the correlation of all three learning theories is used to define a classification of major types of MOOC. Taken together, these theories offer congruent expressions of the essential differences and appropriate applications of MOOCs.

Though pedagogical strategies and design philosophies of individual MOOCs vary widely, an essential distinction can be maintained between xMOOC and cMOOC types. Whereas cMOOCs seek to enable network effects, or demand-side economies of scale in which value is generated by interactions between a massive diversity of participants, xMOOCs seek to maximize supply-side economies of scale in which significant investments in a high quality educational product or service can be leveraged to serve a massive audience of learners. This represents the difference between networked, collaborative learning and expert-driven learning at scale (Herring, 2014). Both of these approaches can result in meaningful learning outcomes and educational innovation. However, there are significant differences in the pedagogical affordances and constraints of content-based xMOOC or network-based cMOOC applications.

Table 1

A Conceptual Model of Theories and Applications of MOOCs

Learning Theories

\section{Prescriptive Learning}

Predictable/complicated

Hierarchical, centrally controlled by experts, replicated and transmitted at scale to users

(Williams, Karousou, \& Mackness, 2011; Williams, Mackness, \& Gumtau, 2012)

\section{Emergent Learning}

Complex/adaptive

Decentralized and distributed, collaborative and selforganized, created at scale by users

\section{$\begin{array}{lll}\text { Cognitive-behaviorist } & \text { Social-constructivist } & \text { Connectivist }\end{array}$}

This work is licensed under a Creative Commons Attribution 4.0 International License. 

Individuals
Individual, stimulated, encoded; knowledge is acquired by individual learners through an expert-designed and scaffolded learning process or training program

\section{Groups/Communities}
Social, participatory, contextual; knowledge is constructed through a process of socialization that negotiates individual experience with multiple perspectives

Crowds/Networks

Distributed, networked, adaptive; knowledge is navigated and activated by making connections across networks of people, information, and resources to address emergent challenges

(Anderson \& Dron, 2011; Downes, 2012; Siemens, 2005)

\section{Pedagogy}

\section{Instructor Control}

Instructor-directed and determined learning; highly structured and controlled; low levels of learner autonomy, self-directedness

\section{Andragogy}

Self-directed learning; learner directs content-focus and learning path with instructor guidance and support; emphasis on competencies and skill development

\section{Heutagogy}

\section{Learner Autonomy}

Self-determined learning; learner fully determines learning goals and processes; emphasis on higher-order capabilities, critical thinking, and learning 'how to learn'

(Beaven, Hauck, Comas-Quinn, Lewis, \& de los Arcos, 2014; Blascke, 2012)

MOOC Applications

xMOOCs

Content-based

One-to-many model; expertdriven learning at scale

\section{Hybrids}

Community and Task-based

Community; guided, social learning activities

\section{cMOOCs}

Network-based

Peer-2-peer; self-organized, networked learning

(Beaven et al., 2014; Lane, 2012; Herring, 2014; Roberts, Waite, Lovegrove, \& Mackness, 2013)

In its idealized form, the xMOOC model can optimize the efficiency of knowledge and competency acquisition (Mazoue, 2013). It offers a formalized approach based on high quality instructional materials and complemented with well-defined learning objectives and assessment procedures. However, this approach has been criticized as operating on regressive pedagogical principles (Guardia, Maina, \& Sangra, 2013; Hollands \& Tirthali, 2014; Rodriguez, 2012; Stacey, 2014). Mackness, Waite, Roberts, and Lovegrove (2013) note: "The pedagogical approach of the massive xMOOCs is currently under scrutiny since some research suggests that large-scale lectures and demonstrations do not support learner understanding” (p. 154). From the perspective of socialconstructivism, the xMOOC model conflicts with research that has demonstrated the importance of social engagement, applied practice, and formative feedback for effective online learning. 
At the other end of the spectrum, the cMOOC model employs a distributed and decentralized approach that facilitates the growth of learner capacities for self-directed and self-determined learning. It offers a participant-driven process, community-generated learning materials, and a strong emphasis on building and growing connections between participants and resources. However, studies have found that participants in cMOOCs are challenged by the "low social presence" contexts of connectivist learning, the learning curve of virtual collaboration tools, and by becoming overwhelmed by information flows and distracted by outside demands (Kop, 2011; Mackness, Mak, \& Williams, 2010). Furthermore, novice participants who become initially overwhelmed by information flows often do not reach the level of active participation (Kop \& Carroll, 2012). Though the goals of cMOOCs may be to facilitate networked learning, the relative lack of course structure and instructor control can be an obstacle for inexperienced and/or less self-directed learners.

\section{Hybrid MOOCs}

The purpose of presenting $\mathrm{xMOOC}$ and cMOOC models as discrete types is to exemplify the essential qualities and strategies of a continuum of MOOC learning. In a certain sense, all MOOCs are hybrids of these approaches. That is, all MOOCs are hybrids insofar as they offer an admixture of multiple pedagogical practices and are co-created by participants who bring their own unique attitudes, needs, and behaviors: "MOOCs offer an unlimited number of possibilities for hybridization because, whatever else, they offer participants the opportunity to fashion their own learning according to their needs" (Roberts, Waite, Lovegrove, \& Mackness, 2013, p. 2). However, following Lane (2012), this study argues that even though all MOOCs may integrate multiple strategies and approaches, each will have an emphasis that is dominant or primary.

Based on patterns of hybridization, a number of recent studies have argued for recognizing additional types of MOOCs (Beaven et al., 2014; Lane, 2012; Roberts et al., 2013). Whereas xMOOCs are recognized as content-based and cMOOCs as networked-based, Roberts et al. (2013) have argued: "Network, content, task, community, project, and blended may all be valid differentiators of MOOCs" (p. 3). Lane (2012) and (Beaven et al., 2014) proposed content-based, task-based, and network-based as three primary types of MOOC. The model proposed in this study amends the middle category ("task-based") as "community and task-based" to better align with theories of online learning and to account for a wider range of MOOC applications. This middle category is typified by a combination of social and instructional support mechanisms. Following social-constructivism, hybrid designs may support learning communities that offer highly social and dialogical learning experiences. Following andragogy, hybrid designs chart a middle path with respect to levels of course structure and learner autonomy. The goal of hybrid design is to balance the strengths and weaknesses of both the xMOOC and cMOOC models for specific audiences and applications.

This work is licensed under a Creative Commons Attribution 4.0 International License. 
The following analysis explores a series of case studies and examples of hybrid MOOC applications. These examples were identified through a review of the research literature and public listings of MOOC courses. Priority was given to case studies that addressed instructional methods and/or learning theories of MOOC design. Additional examples were selected based on use of innovative instructional methods and were analyzed through publicly available course and participant materials. Taken together, the selected examples illustrate a continuum of approaches to hybridizing the essential elements XMOOC and cMOOC models (see Table 2). Furthermore, the analysis addresses appropriate applications and significant design challenges for each of these approaches.

\section{Content-Based Hybrids}

When building on the model of xMOOCs, hybrids have sought to make the most of xMOOCs' high quality content while supporting richer and more intimate social learning experiences. These hybrids have often been based on a blended or flipped course model "that mixes video-based instruction and automated assessment, accessible in a MOOC ... with interactive face-to-face activities: teacher support for deeper understanding of the topics, group projects and problem based learning" (Holotescu \& Grosseck, 2014, p. 2). In this approach, the instructivist methods of xMOOCs are balanced by social-constructivist strategies including an emphasis on supportive social engagement. Whereas typical xMOOC courses are pedagogical and highly-structured, these hybrids incorporate elements of andragogical learning in which learners have greater autonomy to self-direct their own learning and to pursue personalized goals.

Blended or wrapped. One rapidly growing trend in the hybridization of MOOCs is the use of XMOOC materials as the basis for blended courses in traditional university settings. Based on this trend, edX President Anant Agarwal has promoted xMOOCs as "next-generation textbooks" (Holotescu \& Grosseck, 2014). Along these lines, Bruff, Fisher, McEwen, and Smith (2013) report on a case study in which an XMOOC was integrated as the primary content for a blended learning course in a university setting: "Students in an on-campus course are asked to participate in part or in whole in a MOOC hosted at another institution, with the local instructor supplementing that online learning experience with face-to-face classroom interactions" (p. 189). This approach to hybridization can be viewed from two complementary perspectives: blended versions of traditional courses can be economically supported with xMOOC materials, while learning experiences in xMOOCs can be enhanced by being "wrapped" by social learning groups and activities.

A more extensive study of blended learning hybrids based on xMOOCs was completed in the University System of Maryland in 2014. The project involved 17 courses across seven universities using xMOOCs from Coursera and the Open Learning Initiative at Carnegie Mellon. A focused study of seven side-by-side sections from multiple disciplines found that "students in the hybrid sections did as well or slightly better than students in the traditional sections" (Griffiths, Chingos, Mulhern, \& Spies, 2014, p. 4). While both studies emphasized the strong potential of the blended 
MOOC model, they also acknowledged the significant challenges of integrating two course contexts.

In particular, Bruff et al. (2013) noted that students experienced cognitive dissonance in moving between the different learning contexts and styles of instruction of the xMOOC and the local, blended course:

One student commented that the information in the papers was presented in a "less structured format" than the information in the MOOC materials, making the papers seem "less accessible." However, as another student pointed out, the research papers required a "different kind of learning" than the highly structured video lectures. (p. 193)

The XMOOC with its emphasis on prescriptive knowledge, cognitive-behaviorist learning, and pedagogical instructional offered highly structured materials that assumed low levels of selfdirection and adaptation on the part of learners. The more social-constructivist and andragogical approach of the blended course demanded greater self-direction and required learners to engage an established discourse community represented by selected research papers. One challenge of all types of MOOC hybrids is to help learners negotiate diverse learning contexts and levels of autonomy.

Self-organized social networks. Beyond blended learning approaches, individual xMOOC participants have self-organized supportive social networks both inside and outside the formal structures of the course. Participants in xMOOCs have formed online groups in official course forums and on external social media services; they have also organized local study groups and face-to-face meeting through external meet-up services (Glader, 2012). In fact, major xMOOC providers have developed dedicated sites to help participants organize and discover local study and support groups (Goldberg, 2015). Stewart (2013) has argued that despite the centralization and restrictions characteristic of xMOOC platforms, successful xMOOC courses "may end up creating conditions for the development of open, communications-focused, peer-to-peer literacies" (p. 234). The self-organization of online and face-to-face support groups indicate that many xMOOC participants are motivated to move along the spectrum of learning styles and to supplement content-based learning with social, networked, and emergent learning experiences.

\section{Community and Task-based Hybrids}

The middle of the MOOC spectrum presents the greatest diversity of hybrids, typified by community and task-based MOOCs. Task-based MOOCs structure the learning experience through an emphasis on activities, assignments, and/or projects that facilitate engaged practice leading to the development of skills and creation of learning artifacts. Lane (2012) has characterized task-based MOOCs as a "mix of instructivism and constructivism" (para. 5). Many task-based hybrids have also included connectivist and network-based elements. Through an emphasis on structured activities with focused learning objectives, task-based MOOCs provide a

This work is licensed under a Creative Commons Attribution 4.0 International License. 
scaffolded approach to engaging more andragogical or heutagogical experiences and emergent styles of learning (Beaven et al., 2014; Mackness et al., 2013).

Community-based MOOCs typically integrate open network participants with a single smallgroup course at university and/or support a federation of small-group courses across multiple universities. This strategy provides university course participants with a best of both worlds scenario in which the local, small-group environment provides supportive peer and instructor engagement while the wider audience of network participants contributes elements of connectivist-style learning. Complementarily, network participants benefit from the sustained level of engagement generated by the regular contributions of university participants.

Community and task-based. "DS106 Digital Storytelling” (http://ds106.us/) exemplifies this type of hybrid. Although originally offered as an online course at the University of Mary Washington, Levine (2013) has described DS106 as becoming "more community than course" (p. 54). Successive versions of the course have been taught at multiple universities and have integrated a dedicated community of network-based participants (Levine, 2013). Following the distributed network model of cMOOCs, participants produce work hosted on their own individual blogs, social media accounts, and media hosting accounts (soundcloud, vimeo, youtube, etc.). These learning artifacts are then aggregrated and shared for public engagement and discussion on the main course site.

The most significant contribution of DS106 is its unique hybridization of community and taskbased learning strategies. Course activities are built around two central features: a crowd-sourced "Assignment Bank" (http://assignments.ds106.us/) and "Daily Create" (http://tdc.ds106.us/) quick assignments. Stacey (2014) has argued that the Assignment Bank "model of having course participants collectively build the course assignments which are then used by students in future classes is a hugely significant pedagogical innovation" (p. 113). Not only do all participants contribute assignments, but the community rates the challenge/time commitment of each assignment based on a five-point scale. The course is based on the completion of a certain number points of each main type of assignment. Thus, participants have significant freedom to self-direct and self-determine their learning while the assignment bank provides a task-based structure supporting their efforts. This co-creation and assessment of assignments also aligns with academic values of peer review and community knowledge generation. This synthesis of community and task-based strategies illustrates the complementary relationship of socialconstructivism and andragogy.

The second essential aspect of the DS106 course structure is the Daily Create. As the Daily Create site explains, these daily assignments provide "a space for the regular practice of spontaneous creativity" and "should take no more than 15-20 minutes" (para. 2). In addition to promoting the development of capacities for creativity and adaptability in digital media authorship, these brief assignments are designed to directly engage learners in the active production of learning artifacts. The Daily Create lowers the threshold of active participation; it offers a novel strategy for "short- 
circuiting" a typical cycle of passive consumption and active production. Rather than risk losing participants to passive consumption and inactivity, DS106 flips the sequence of learning so that learners begin with active production of learning artifacts and proceed to passive consumption to support their work.

Community-based. The self-described distributed open collaborative course (DOCC) hosted by FemTechNet in 2013 exemplifies a primarily community-based hybrid. "Dialogues on Feminism and Technology" (http://femtechnet.newschool.edu/docc2013/) was developed through the shared effort of over 30 different instructors from many different institutions (FemTechNet White Paper Committee, 2013). The course was structured to encourage participation from formal university courses, individual scholars and faculty, ad hoc study groups, and individual student participants. The rationale and instructional methods of this course are strongly social-constructivist in orientation including an emphasis on dialogue, a diversity of perspectives, and socially-negotiated knowledge production. This approach is also contingent on a flexible course structure that allows significant learner autonomy to self-determine participation as in andragogy.

Another interesting feature of this course is that it grew out of an established online community. Rather than solely addressing traditional functions of university-based learning, this course also promoted the growth and broader mission of the FemTechNet community (Juhasz \& Balsamo, 2012). This suggests that societies and organizations might lead MOOCs in order to promote specific projects/initiatives, build stronger relationships among current members, and attract new ones.

Task-based. For an example of a primarily task-based hybrid, consider "First Steps in Learning and Teaching” (FSLT12) (http://openbrookes.net/firststeps12/). Self-described as a "small, task-based cMOOC," this 2012 course was developed to support "new lecturers, PhD students who teach, and people moving into HE from industry" (Mackness et al., 2013, p. 142). Given this audience, the course design integrated several significant support structures for its participants, most significantly the use of “MOOC 'veterans' ... as role models and guides" (p. 140). This strategy addresses the findings that "[t]he more active or experienced members of the group provide a model for those who are less experienced, and are instrumental in creating the emergent spaces supporting connectedness and interactivity" (Milligan et al., 2013, p. 156). Additionally, the course provided extensive scaffolding for social and technical skills and taskbased design for learning activities.

Though modeled on the heutagogic contexts of connectivism, this emphasis on social support and course structure frames a more andragogical and social-constructivist influenced experience. In a case study of FSLT12, Mackness et al. (2013) noted that participants reported encountering challenges similar to those reported by other studies of connectivist learning including adapting to distributed learning environments, collaborative learning styles, managing online identities, and overcoming the inherent uncertainty of emergent learning. However, the combination of peer 
mentorship and task-based learning strategies proved a successful means of supporting novice participants. The results of this case-study strongly support the value of task-based instruction as a means of scaffolding emergent learning experiences.

A second example of a primarily task-based hybrid is OTL12, a 2012 course exploring "translation tools and practices" (Beaven et al., 2014, p. 32). OTL12 employed similar support mechanisms to FSLT12 while supporting learners with professional experience in translation of multiple different languages. In a case study of OTL12, Beaven et al. (2014) cited the challenges of designing for diverse participants and learning styles. Although OTL12 framed itself as a hybrid of task and networked-based approaches, a pre-course survey found that most participants held learning goals and expectations more consistent with content and task-based learning. Furthermore, most participants expected high levels of guidance, support, and feedback from the course leaders. These expectations were corroborated by post-course surveys in which some participants reported frustration with the open and self-determined aspects of the experience. However, participants also reported growth in participatory learning skills, appreciation for networking and social learning opportunities, and examples of serendipitous learning. This suggests that learners value a balance of social-constructivist and connectivist learning experiences including course structures that scaffold movement from andragogy to heutagogy.

\section{Network-based Hybrids}

Hybrids based on the cMOOC model have sought to build on the promise of connectivist learning while providing additional support for overcoming technological barriers and the challenges of heutagogical learning. The essential marker of these hybrids is a network-based course design that integrates scaffolding for technology skills and/or provides structured approaches to learning activity and social engagement. Relative to hybrids that are primarily community or task-based, network-based hybrids typically address more distributed and diverse audiences while maintaining a primary emphasis on learner autonomy and on enabling open-ended learning experiences.

Network-based. Examples of this type of hybrid include "Educational Technology and Media" (ETMOOC) (http://etmooc.org/). Offered in the spring of 2013, this course supported professional development for researchers and practitioners across both secondary and postsecondary contexts. Closely resembling the model of previous cMOOCs, ETMOOC innovated by devoting one of its six weeks to an orientation that provided task-based instruction for using course technologies and offered networking and social orientation activities. Furthermore, the course included scaffolding for facilitators and session leaders to increase the effectiveness of a distributed approach to leading course activities and mentoring novice participants. This distributed leadership model proved extremely robust and led to a strong sense of communityownership of the course. Though it has been two years since ETMOOC officially ended, participants have continued to self-organize regular online discussions, learning events, and maintain active social media groups (Levine, 2015).

This work is licensed under a Creative Commons Attribution 4.0 International License. 
The late spring 2013 course, "OCTEL: Open Course in Technology Enhanced Learning" (http://octel.alt.ac.uk/), also provided a week-long orientation, but went further by employing a number of active learning and participant engagement strategies. Each week offered a curated list of readings as is typical in cMOOC courses; however, the course also provided a series of taskbased assignments supporting a diversity of learning styles and levels of social engagement. Each week included an "If you only do one thing ..." assignment. This assignment functioned much like the "Daily Create" in DS106; it lowered the threshold of engagement and sought to convert passive participation to active participation. Finally, a badging system incentivized and tracked participation for both individuals and the community (Hawksey, 2014). As in earlier cMOOCs, learning activities facilitated the creation of learning artifacts that were shared and discussed with the course community through aggregation channels.

In a study of cMOOC participation patterns, Milligan et al. (2013) found that three primary factors contributed to the active participation of learners: "prior cMOOC experience, confidence, and motivation" (p. 15). Designers of cMOOCs and network-based hybrids may help participants develop all three by incorporating elements of community and task-based designs. This could include the use of mentors, networking activities to engage novices, learning activities that focus on specific tasks and skill sets, and activities designed to lower the threshold of active participation.

Table 2

A Taxonomy of Hybrid MOOC Design

\section{Hybrid MOOC Design}

\begin{tabular}{llll}
\hline & xMOOCs & Hybrids & cMOOCs \\
Primary Types & Content-based & $\begin{array}{l}\text { Community and Task- } \\
\text { based }\end{array}$ & Network-based \\
& $\begin{array}{l}\text { One-to-many model; } \\
\text { expert-driven learning at } \\
\text { scale }\end{array}$ & $\begin{array}{l}\text { Community; guided, social } \\
\text { learning activities }\end{array}$ & $\begin{array}{l}\text { Peer-2-peer; self- } \\
\text { organized, networked } \\
\text { learning }\end{array}$ \\
$\begin{array}{l}\text { Learning } \\
\text { Theories }\end{array}$ & $\begin{array}{l}\text { Prescriptive } \\
\text { Cognitive-behaviorist } \\
\text { Pedagogy }\end{array}$ & $\begin{array}{l}\text { Prescriptive/Emergent } \\
\text { Social-constructivist } \\
\text { Andragogy }\end{array}$ & $\begin{array}{l}\text { Emergent } \\
\text { Connectivist } \\
\text { Heutagogy }\end{array}$ \\
$\begin{array}{l}\text { MoOC } \\
\text { Applications }\end{array}$ & $\begin{array}{l}\text { Blended and Wrapped } \\
\text { xMOOCs }\end{array}$ & $\begin{array}{l}\text { DS106, DOCC13, FSLT12, } \\
\text { OTL12 }\end{array}$ & ETMOOC13, OCTEL13 \\
\hline
\end{tabular}




\section{Discussion}

The theoretical and empirical research analyzed in this study strongly indicate that both xMOOC and cMOOC models are most effective when supplemented with community and task-based instructional strategies in alignment with social-constructivist and andragogical learning theories. By supplementing $\mathrm{xMOOC}$ and $\mathrm{cMOOC}$ experiences with social interaction, community engagement, and supportive course structures that scaffold technology-use and self-determined learning, hybrid MOOC designs enable the benefits of economies of scale at a human scale.

\section{Hybrid Design Strategies}

The primary design challenge for all types of MOOCs is promoting sustained active participation. Clow (2013) has theorized a "funnel of participation" model which characterizes the "steep dropoff in activity and the pattern of unequal participation, which appear to be characteristic of MOOCs and similar learning environments" (p. 1). Multiple studies have indicated that observers, drop-ins, and passive participants outnumber active participants across all types of MOOCs (Clow, 2013; Hill, 2013; Milligan et al., 2013; Waite, Mackness, Roberts, \& Lovegrove, 2013). Both community-based and task-based design strategies offer ways to address this challenge.

Community-based strategies strongly relate to theories of social-constructivism, but can also address connectivist and network-based social interactions. A recent study found significant numbers of participants in all types of MOOC "exhibit the agency to engage with the course on [external] platforms" by connecting with other participants through external media channels and by discussing their learning experiences with "individuals who are part of their broader social network" (Veletsianos, Collier, \& Schneider, 2015, p. 580). Just as xMOOC participants have selforganized to engage in social learning experiences, content-based hybrids including blended or wrapped courses have supplemented one-to-many instruction with cohort-based face-to-face meetings. Community and task-based hybrids have designed learning that involves social engagement including small group activities and/or learning that contributes to the development of shared values and knowledge. Multiple hybrids including network-based designs have integrated the use of distributed leadership and facilitation strategies that help connect novice learners with more experienced learners. The clear indication is that significant numbers of MOOC participants and learners are self-motivated to socialize their experience. Effective hybrid designs offer social experiences that enhance engagement and allow learners to build relationships, communities, and social networks as they construct new knowledge and develop new skills.

Task-based instructional strategies can be framed in terms of andragogy and heutagogy: participants in all types of MOOCs need supportive structures that help promote and enable the active exercise of autonomous learning. First and foremost, task-based course designs can promote active participation by enabling and focusing learning through the completion of specific goals and development of discrete skills. Multiple hybrid designs have sought to make task-based

This work is licensed under a Creative Commons Attribution 4.0 International License. 
activities more effective by lowering the cost of active participation and/or narrowing the focus and goals of learning. For example, DS106 has employed the "Daily Create" assignment as strategy for engaging participants first and foremost as creators and producers rather than as consumers of course materials. Similarly, OCTEL13 offered a "If you only do one thing ..." assignment that helped focus and streamline learning activities and promote active engagement. Multiple hybrid courses also provided in depth orientation activities and tutorial materials to help novice learners adapt to course technologies and network-based learning experiences. Designing for active participation in MOOCs requires addressing the needs of participants with diverse learning capacities, expectations, and goals.

\section{Future Applications of Hybrid Design}

Analysis of these case studies has also helped identify promising applications of hybrid MOOC design. The greatest growth potential is for content-based hybrids in which blended or wrapped courses are developed based on XMOOC materials. In higher education and university settings, content-based hybrids could have valuable applications for both large-scale general education courses and highly-specialized topics. Hybrids based on xMOOCs will ideally offer a balanced mixture of high-quality instructional materials and social learning experiences that depend on leveraging both economies of scale and local expertise.

Hybrid MOOCs that integrate community and task-based strategies can support the values of networked, emergent learning while also providing social contexts and learning structures that enable sustained active participation. One promising application of this type of hybrid is the cross-institutional course. As Caulfield, Collier, and Halawa (2013), suggested: "The key element connecting experiments such as these is that the differences in the local versions of each class are seen not as deviations but as net benefits to the cross-institutional community; the dialogue among students in different classes is meant to foster a diverse community of learners" (para. 23). In addition to university-based efforts, community-based MOOC hybrids may also have applications for extra-institutional communities. Whether academic or professional in focus, these communities can use MOOCs to catalyze growth, build relationships, inaugurate projects, and disseminate knowledge.

As noted in case studies of task-based hybrids, even in courses that include social and instructional scaffolding, participants may be challenged by the necessity of adapting their expectations and learning styles for networked learning environments. However, these studies also indicate that self-motivated learners who engage the potential of networked learning can develop both appreciation and capacities for more self-directed and self-determined learning styles. Thus, community and task-based hybrids may be especially suited to support the growth of learners along the spectrum of learning styles including developing capacities for heutagogical learning. In particular, Mackness et al. (2013) argued small-scale task-based hybrids may prove a viable application of MOOCs for university courses to both facilitate "open professional development” and introduce new learners to network-based learning experiences (p. 155).

This work is licensed under a Creative Commons Attribution 4.0 International License. 
Network-based hybrids are valuable for connecting distributed interest groups and enabling situated problem-solving, professional development, and lifelong learning. In a 2014 study of professional learners in an xMOOC, Milligan and Littlejohn noted that instructivist-based course structures have limited value for professional learning:

Professionals have precise learning needs, based on their role, background and motivations. A professional learning MOOC could encourage professional learners to take ownership of their learning by asking them to set personal goals, or at least personalise course goals that link theory to their own practice. The MOOC design could also exploit the existing knowledge of its professional learners as a core course resource. (p. 210).

The connectivist and heutagogical environments of network-based hybrids are ideal for facilitating this type of personalized, professionalized, and situated learning. Furthermore, research shows that heutagogical learning contributes to the development of higher order capacities for learning including: "learner control of learning, collaborative reflection, learner's self-perception and professional development, and critical thinking and reflection" (Blaschke, 2012, p. 64). More broadly, networked learning including heutagogical, connectivist, and/or participatory designs has been shown to have a significant impact on high order thinking and meta-cognitive development (Beaven et al., 2013; McLoughlin \& Lee, 2008; Saadatmand \& Kumpulainen, 2014). By scaffolding the experience of connectivist learning, hybrid cMOOCs may help participants unlock its uniquely valuable learning outcomes.

\section{Further Research}

This study proposes a conceptual model based on a synthesis of the theoretical literature. This model is supported with evidence from representative case examples. Based on a close analysis of hybrid design, this study finds that a balance of design styles is ideal for supporting diverse learners and can contribute to helping individuals develop capacities for more autonomous and networked learning styles. Though grounded in theory and empirical results, these findings are based on a limited sample of MOOCs and hybrid designs. Additional research will be necessary to answer several significant research questions related to the findings of this study. First, what are design patterns and trends among a large sample of MOOC courses including all major providers? Which learning theories and strategies are practitioners of all types using to guide their course designs? Second, additional empirical study will be necessary to understand the impact of hybrid MOOC designs on individual learners and their development of heutagogical, connectivist, and emergent learning capacities.

This work is licensed under a Creative Commons Attribution 4.0 International License. 


\section{Conclusion}

Though all types of MOOC hybrids offer opportunities for meaningful innovation, there are significant differences in their affordances. Content-based hybrids employ high quality instructional materials as the building blocks of blended learning experiences. Community-based hybrids offer socially-engaging experiences that contribute to the development of shared values, shared knowledge, and/or collective goals. Task-based hybrids support the development of discrete skills and/or completion of specific projects. Network-based hybrids facilitate the growth of self-organized social networks and the development of emergent knowledge that addresses situated problems.

One clear value of hybrid approaches to MOOC design is that a balance of instructional strategies may best support participant progress along a continuum of learning styles. Hybrid MOOCs can provide supportive environments in which participants develop the experience and confidence necessary to be successful in more open and distributed learning contexts. By designing experiences that intersect with advanced academic and professional contexts, these experiences can engage learners who are intrinsically motivated to leverage the learning in the service of problem solving and professional growth. Ultimately, hybrid MOOC designs may support the greatest diversity of learners and contribute the growth of the greatest diversity of learning capacities.

\section{References}

Anderson, T., \& Dron, J. (2011). Three generations of distance education pedagogy. International Review of Research in Open and Distance Learning, 12(3), 80-97. Retrieved from http://www.irrodl.org/index.php/irrodl/article/view/89o/

Beaven, T., Hauck, M., Comas-Quinn, A., Lewis, T., \& de los Arcos, B. (2014). MOOCs: Striking the Right Balance between Facilitation and Self-Determination. MERLOT: Journal of Online Learning and Teaching, 1O(1), 31-43. Retrieved from http://jolt.merlot.org/voliono1/beaven 0314.pdf

Blaschke, L. M. (2012). Heutagogy and lifelong learning: A review of heutagogical practice and self-determined learning. The International Review of Research in Open and Distance Learning, 13(1), 56-61. Retrieved from http://www.irrodl.org/index.php/irrodl/article/view/1076/2087

Bruff, D. O., Fisher, D. H., McEwen, K. E., \& Smith, B. E. (2013). Wrapping a MOOC: Student perceptions of an experiment in blended learning. MERLOT Journal of Online Learning 
and Teaching, 9(2), 187-199. Retrieved from

http://jolt.merlot.org/volgno2/bruff 0613.htm

Caulfield, M., Collier, A., \& Halawa, S. (2013). Rethinking online community in MOOCs used for blended learning. Educause Review Online, 1-9. Retrieved from http://www.educause.edu/ero/article/rethinking-online-community-moocs-usedblended-learning

Clow, D. (2013). MOOCs and the funnel of participation. Proceedings of the Third International Conference on Learning Analytics and Knowledge - LAK'13, 185. doi:10.1145/2460296.2460332

Downes, S. (2012). Connectivism and connective knowledge: Essays on meaning and learning networks. National Research Council Canada. Retrieved from http://www.downes.ca/files/books/Connective Knowledge-19May2012.pdf

FemTechNet White Paper Committee: Balsamo, A., Boyer, P., Fernandes, M., Gajjala, R., Irish, S., Junasz, A., Losh, E., Rault, J., \& Wexler, L. (2013). Transforming higher education with distributed open collaborative courses ( DOCCs ): Feminist pedagogies and networked learning. FemTechNet. Retrieved from http://femtechnet.newschool.edu/femtechnetwhitepaper/

Fischer, G. (2014). Beyond hype and underestimation: Identifying research challenges for the future of MOOCs. Distance Education, 35(2), 149-158. doi:10.1080/01587919.2014.920752

Gartner, Inc. (2014). Gartner hype cycle. Retrieved from http://www.gartner.com/technology/research/methodologies/hype-cycle.jsp/

Glader, P. (2012, October 3). MOOC meetup groups point to a blended (online + community) learning model. WiredAcademic. Retrieved from http://www.wiredacademic.com/2012/10/mooc-meetup-groups-point-to-a-blendedonline-community-learning-model/

Goldberg, M. (2015, January 28). MOOCs and meetups together make for better learning. Huffington Post College. Retrieved from http://www.huffingtonpost.com/michaelgoldberg/moocs-and-meetupstogethe b 6538414.html

Griffiths, R., Chingos, M., Mulhern, C., \& Spies, R. (2014). Interactive online learning on campus: Testing MOOCs and other platforms in hybrid formats in the University 
System of Maryland. Ithaka S+R. Retrieved from http://www.sr.ithaka.org/wpcontent/mig/reports/S-R Interactive Online Learning Campus 20140710.pdf

Guàrdia, L., Maina, M., \& Sangrà, A. (2013, May). MOOC design principles. A pedagogical approach from the learner's perspective. eLearning Papers, 33, 1-6. Retrieved from http://www.elearningpapers.eu/sites/default/files/asset/In-depth_33_4_o.pdf

Hawksey, M. (2014, June 11). MASHe ALT innovates : A BadgeOS WordPress plugin add-on to host and issue Mozilla open badges. MASHe. Retrieved from https://mashe.hawksey.info/2014/o6/alt-innovates-a-badgeos-mozilla-open-badgesissuer-addon/

Herring, S. (2014, January). MOOCs come of age. $T+D, 46-50$. Retrieved from https://www.td.org/Publications/Magazines/TD/TD-Archive/2014/01/Moocs-Come-ofAge

Hill, P. (2012). Online educational delivery models: A descriptive view. Educause Review Online, 84-97. Retrieved from http://www.educause.edu/ero/article/online-educationaldelivery-models-descriptive-view

Hill, P. (2013, March 10). Emerging student patterns in MOOCs: A graphical view. E-Literate. Retrieved from http://mfeldstein.com/emerging_student_patterns_in_moocs_graphical_view

Hollands, F. M., \& Tirthali, D. (2014). MOOCs: Expectations and reality. Center for Benefit-Cost Studies of Education, Teachers College, Columbia University. Retrieved from http://www.academicpartnerships.com/sites/default/files/MOOCs_Expectations_and Reality.pdf

Holotescu, C., \& Grosseck, G. (2014). Integrating MOOCs in blended courses. In The 1oth International Scientific Conference eLearning and software for Education (pp. 478483). Retrieved from https://www.academia.edu/6503489/Integrating_MOOCs_in_Blended_Courses

Juhasz, a, \& Balsamo, a. (2012). An idea whose time is here: FemTechNet, a distributed online collaborative course (DOCC). Journal of Gender, New Media and Technology, 1(1). doi:10.7264/N3MW2F2J

Kop, R. (2011). The challenges to connectivist learning on open online networks: Learning experiences during a massive open online course. International Review of Research in Open and Distanced Learning, 12(3), 19-38. Retrieved from http://www.irrodl.org/index.php/irrodl/article/view/882 
Kop, R. (2012). The unexpected connection: Serendipity and human mediation in networked learning. Educational Technology and Society, 15, 2-11. Retrieved from http://www.ifets.info/journals/15 2/2.pdf

Kop, R., \& Carroll, F. (2012). Cloud computing and creativity: Learning on a massive open online course. European Journal of Open, Distance and E-Learning, 1-11. Retrieved from http://www.eurodl.org/materials/special/2011/Kopp Carroll.htm

Lane, L. M. (2012, August 15). Three kinds of MOOCs. Retrieved from http://www.lisahistory.net/wordpress/2012/o8/three-kinds-of-moocs/

Levine, A. (2013, January). ds106: Not a course, not like any MOOC. Educause Review Online, 54-55. Retrieved from http://www.educause.edu/ero/article/ds106-not-course-not-anymooc/

Levine, A. (2015, May 28). The cMOOC that would not die. CogDogBlog. Retrieved from http://cogdogblog.com/2015/05/28/the-cmooc-that-would-not-die/

Liyanagunawardena, T., Adams, A., \& Williams, S. (2013). MOOCs: A systematic study of the published literature 2008-2012. The International Review Of Research In Open And Distance Learning, 14(3), 202-227. Retrieved from http://www.irrodl.org/index.php/irrodl/article/view/1455/2531

Mackness, J., Mak, S. F. J., \& Williams, R. (2010). The ideals and reality of participating in a MOOC. In L. Dirckinck-Holmfeld, V. Hodgson, C. Jones, M. De Laat, D. McConnell, \& T. Ryberg (Eds.), Proceedings of the 7th International Conference on Networked Learning, 10, pp. 266-274. University of Lancaster. Retrieved from http://www.lancs.ac.uk/fss/organisations/netlc/past/nlc2010/abstracts/PDFs/Macknes s.pdf

Mackness, J., Waite, M., Roberts, G., \& Lovegrove, E. (2013). Learning in a small, task-oriented, connectivist MOOC: Pedagogical issues and implications for higher education. International Review of Research in Open and Distance Learning, 14, 140-159. Retrieved from http://www.irrodl.org/index.php/irrodl/article/view/1548/2636

Mazoue, J. (2013). The MOOC model: Challenging traditional education. Educause Review Online, 1-7. Retrieved from http://er.dut.ac.za/handle/123456789/71

McLoughlin, C., \& Lee, M. J. W. (2008). The three P's of pedagogy for the networked society: Personalization, participation, and productivity. International Journal of Teaching and Learning in Higher Education, 2O(1), 10-27. Retrieved from http://www.isetl.org/ijtlhe/pdf/IJTLHE395.pdf 
Milligan, C., Littlejohn, A., \& Margaryan, A. (2013). Patterns of engagement in connectivist MOOCs. MERLOT Journal of Online Learning and Teaching, 9(2), 149-159. Retrieved from http://jolt.merlot.org/volgno2/milligan 0613.htm

Milligan, C., \& Littlejohn, A. (2014). Supporting professional learning in a massive open online course. The International Review of Research in Open and Distance Learning, 15(5), 197-213. Retrieved from http://www.irrodl.org/index.php/irrodl/article/view/1855

Pappano, L. (2012, November 2). The year of the MOOC. The New York Times. Retrieved from http://www.nytimes.com/

Poplar, D. (2014). MOOC evolution and one poetry MOOC's hybrid approach. Educause Review Online. Retrieved from http://www.educause.edu/ero/article/mooc-evolution-and-onepoetry-mooc's-hybrid-approach /

Roberts, G., Waite, M., Lovegrove, E. J., \& Mackness, J. (2013). x v c: Hybridity in through and about MOOCs. In Creating a virtuous circle: Proceedings of OER13. Milton Keynes, UK: The Open University, Support Centre for Open Resources in Education. Retrieved from http://openbrookes.net/firststeps12/files/2012/08/OER13ExtendedAbstractHybridLearningGR-JM-040213.pdf

Rodriguez, C. O. (2012). MOOCs and the AI-stanford like courses: Two successful and distinct course formats for massive open online courses. European Journal of Open, Distance and E-Learning. Retrieved from http://www.eurodl.org/index.php?p $=$ currentarticle $=357 \&$ article $=516$

Saadatmand, M., \& Kumpulainen, K. (2013). Content aggregation and knowledge sharing in a personal learning environment: Serendipity in open online networks. International Journal of Emerging Technologies in Learning (iJET), 8(S1), 70-77. doi:10.3991/ijet.v8iS1.2362

Saadatmand, M., \& Kumpulainen, K. (2014). Participants' perceptions of learning and networking in connectivist MOOCs. MERLOT: Journal of Online Learning and Teaching, 1O(1), 1630. Retrieved from http://jolt.merlot.org/voliono1/saadatmand_0314.pdf

Selingo, J. (2014, Oct 29). Demystifying the MOOC. New York Times. Retrieved from http://www.nytimes.com/

Shah, Dhawal (2014, Dec 26). MOOCs in 2014: Breaking down the numbers. edSurge. Retrieved from https://www.edsurge.com/n/2014-12-26-moocs-in-2014-breaking-down-thenumbers/ 
Siemens, G. (2005). Connectivism: A learning theory for the digital age. Retrieved from http://www.elearnspace.org/Articles/connectivism.htm

Siemens, G. (2006). Connectivism: Learning theory or pastime of the self-amused? Manitoba, Canada: Learning Technologies Centre. Retrieved from http://altamirano.biz/conectivismo.pdf

Stacey, P. (2014). Pedagogy of MOOCs. INNOQUAL: International Journal for Innovation and Quality in Learning, 2(3), 111-115. Retrieved from http://www.openeducationeuropa.eu/en/article/Pedagogy-of-MOOCs

Stewart, B. (2013). Massiveness + Openness $=$ New literacies of participation? MERLOT Journal of Online Learning and Teaching, 9(2), 228-238. Retrieved from http://jolt.merlot.org/volgno2/stewart_bonnie_0613.htm

Veletsianos, G., Collier, A., \& Schneider, E. (2015). Digging deeper into learners' experiences in MOOCs: Participation in social networks outside of MOOCs, notetaking and contexts surrounding content consumption. British Journal of Educational Technology, 46(3), 570-587. doi:10.1111/bjet.12297

Waite, M., Mackness, J., Roberts, G., \& Lovegrove, E. (2013). Liminal participants and skilled orienteers: Learner participation in a MOOC for new lecturers. MERLOT Journal of Online Learning and Teaching, 9(2), 200-215. Retrieved from http://jolt.merlot.org/volgno2/waite_o613.htm

Williams, R., Karousou, R., \& Mackness, J. (2011). Emergent learning and learning ecologies in Web 2.o. The International Review of Research in Open and Distance Learning, 12(3), 39-59. Retrieved from http://www.irrodl.org/index.php/irrodl/article/view/883/1729

Williams, R., Mackness, J., \& Gumtau, S. (2012). Footprints of emergence. The International Review of Research in Open and Distance Learning, 13(4), 49-90. Retrieved from http://www.irrodl.org/index.php/irrodl/article/view/1267/2308 